\title{
Do cardiovascular disease risk prediction tools need to be updated in Europe?
}

\author{
Ilker Tasci
}

Received: 27 April 2011/Accepted: 24 May 2011/Published online: 11 June 2011

(c) SIMI 2011

Dr. Cimminiello and colleagues in their well-designed trial, examined the frequency of peripheral arterial disease (PAD) in patients with nonhigh cardiovascular risk in six countries of Europe [1]. The PANDORA study may not be the first of its kind, but the results presented by the authors deserves attention concerning the higher frequency of PAD in two Mediterranean countries Italy $(22.9 \%)$ and Greece (28\%) when compared to France (12.2\%), Switzerland (12.2\%), The Netherlands (8.1\%) and Belgium (8.1\%). It is noteworthy that the four countries with the highest prevalence of PAD in people with nonhigh risk profile for cardiovascular disease in the study are accepted as low risk countries in European guidelines on cardiovascular disease prevention published in 2007 [2]. Moreover, The Netherlands, which is indicated as a high risk country in the same guidelines displays a relatively lower frequency of the disease, not more than Belgium which is also a low risk country. The results are quite different, and, unless supported by scientific evidence, cannot easily be explained by methodological discrepancies in the recorded countries. Such big changes in the magnitude of the disease is also not likely in a couple of years.

As we know, 2007 European guidelines and score charts were designed to estimate the probability of all types of cardiovascular diseases including PAD [2]. While trying to establish the benefits of a Mediterranean lifestyle, the PANDORA study suggests that we should also focus on whether we need to upgrade the current risk stratification

I. Tasci $(\bowtie)$

Department of Internal Medicine and Geriatrics,

Gulhane School of Medicine,

GATA Ic Geriatri Bilim Dali,

Etlik 06018, Ankara, Turkey

e-mail: ilkertasci@yahoo.com models for some countries. Indeed, we recently published the results of a nationwide survey in Turkey, the CAREFUL study, which finds that the prevalence of a low ABI in a target population is 20\% [3]. The major difference between the two studies is inclusion of diabetics and people with established cardiovascular diseases other than PAD in the CAREFUL study. While the frequency of PAD in Turkey initially seemed higher than expected, we now recognize that the burden of the disease in countries labeled with low cardiovascular risk is higher than that estimated, and is sufficient enough to update our understanding.

Conflict of interest None.

\section{References}

1. Cimminiello C, Kownator S, Wautrecht JC, Carvounis CP, Kranendonk SE, Kindler B, Mangrella M, Borghi C, for the PANDORA Study Investigators (2011) The PANDORA study: peripheral arterial disease in patients with non-high cardiovascular risk. Intern Emerg Med. doi:10.1007/s11739-011-0511

2. Graham I, Atar D, Borch-Johnsen K et al (2007) European guidelines on cardiovascular disease prevention in clinical practice: executive summary: fourth joint task force of the european society of cardiology and other societies on cardiovascular disease prevention in clinical practice (constituted by representatives of nine societies and by invited experts). Eur $\mathbf{J}$ Cardiovasc Prev Rehabil 14(Suppl 2):E1-E40

3. Bozkurt AK, Tasci I, Tabak O, Gumus M, Kaplan Y (2011) Peripheral artery disease assessed by ankle-brachial index in patients with established cardiovascular disease or at least one risk factor for atherothrombosis-careful study: a national, multicenter, cross-sectional observational study. BMC Cardiovasc Disord 11:4 